\title{
OxLDL plasma levels in patients with Alzheimer's disease
}

\author{
Niveis plasmáticos de LDL-ox em pacientes com doença de Alzheimer \\ Marina Felipe Grossi', Maria das Graças Carvalho', Josianne Nicácio Silveira', Gisele Santos Gonçalves ${ }^{1,2}$, \\ Karina Braga Gomes ${ }^{1}$, Maria Aparecida Bicalho ${ }^{3,4}$, leda de Fátima Oliveira Silva ${ }^{1}$
}

\begin{abstract}
Objective: The objective of this study was to characterize the conventional lipid profile, oxLDL levels and ApoE polymorphism in patients with Alzheimer's disease (AD) and in elderly individuals without cognitive impairment. Methods: Eighty elderly individuals were selected and the levels of oxLDL were determined using the ELISA kit, and ApoE gene polymorphism was investigated using polymerase chain reaction-restriction fragment length polymorphism. Results: Significantly reduced levels of oxLDL were observed in patients with $A D$ compared to the control group. A higher frequency of the ApoE $\varepsilon 4$ allele was observed in patients with AD compared to controls. No difference was observed for total cholesterol, HDL-C, and LDL-C levels between the two groups, while triglyceride levels were higher in controls compared with patients with AD. Conclusion: The data analyzed together did not reveal significant differences in lipid profiles, including oxLDL levels. However, the importance of lipid changes in the genesis of the disease cannot be ruled out. Nevertheless, the ApoE $\varepsilon 4$ allele was significantly more frequent in patients with Alzheimer's dementia in agreement with previous findings in the literature, but this genetic component did not change the levels of oxLDL.
\end{abstract}

Keywords: Alzheimer's disease; Cholesterol, LDL.

\section{RESUMO}

Objetivo: O objetivo deste estudo foi caracterizar o perfil lipídico convencional, os níveis de LDL-ox e o polimorfismo da ApoE em pacientes com doença de Alzheimer (DA) e em indivíduos idosos sem comprometimento cognitivo. Métodos: Foram selecionados oitenta indivíduos idosos. Os níveis de LDL-ox foram determinados usando o kit ELISA e a investigação do polimorfismo do gene da ApoE por PCR-RFLP. Resultados: Níveis significativamente reduzidos de LDL-ox foram observados em pacientes com DA comparado ao grupo controle. Uma maior frequência do alelo $\varepsilon 4$ da ApoE foi observada nos pacientes com DA em relação aos controles. Nenhuma diferença foi observada para os níveis de colesterol total, HDL-C e LDL-C entre os dois grupos, enquanto níveis de triglicérides foram mais altos em controles comparados aos pacientes com DA. Conclusão: Os dados analisados em conjunto não revelaram diferenças significativas no perfil lipídico, incluindo os níveis de LDL-ox. No entanto, não se pode excluir a importância de alterações lipídicas na gênese da doença. Não obstante, o alelo $\varepsilon 4$ da ApoE foi signicativamente mais frequente nos pacientes com demência de Alzheimer em concordância com achados prévios da literatura, mas esse componente genético não interferiu nos níveis de LDL-ox.

Palavras-chave: Doença de Alzheimer, LDL-colesterol.

Several studies have correlated dyslipidemia and Alzheimer's disease $(\mathrm{AD})$, mainly by considering the increase of both total cholesterol (TC) and low density lipoprotein cholesterol (LDL-C) and reduced high density lipoprotein cholesterol $(\mathrm{HDL}-\mathrm{C})^{1,2}$. In addition, oxidative stress in the central nervous system can cause oxidation of LDL-C (oxLDL) and very lowdensity lipoprotein (oxVLDL), which determines cytotoxicity ${ }^{3}$.
Studies have suggested that oxidative stress may be involved in the pathogenesis of $\mathrm{AD}^{4,5}$. According to Pirillo et al. ${ }^{6}$, oxLDL plays an important role in the initiation and progression of atherosclerotic plaques contributing to endothelial cell activation and dysfunction, foam cell formation, and migration and proliferation of smooth muscle cells. Therefore, oxLDL induces endothelial dysfunction and shows pro-inflammatory and

\footnotetext{
1 Universidade Federal de Minas Gerais, Faculdade de Farmácia, Departamento de Análises Clínicas e Toxicológicas, Belo Horizonte MG, Brasil;

${ }^{2}$ Centro Universitário Newton Paiva, Belo Horizonte MG, Brasil;

${ }^{3}$ Universidade Federal de Minas Gerais, Hospital das Clínicas, Instituto Jenny de Andrade Faria, Ambulatório de Idosos, Belo Horizonte MG, Brasil;

«Universidade Federal de Minas Gerais, Faculdade de Medicina, Departamento de Clínica Médica, Belo Horizonte MG, Brasil.
}

Correspondence: lêda de Fátima Oliveira Silva; Faculdade de Farmácia da UFMG; Avenida Antônio Carlos, 6627; $31270-901$ Belo Horizonte MG, Brasil; E-mail: iedafos@farmacia.ufmg.br

Conflict of interest: There is no conflict of interest to declare.

Support: FAPEMIG (Fundação de Amparo à Pesquisa de Minas Gerais) and CNPq (Conselho Nacional do Desenvolvimento da Pesquisa).

Received 13 July 2017; Received in final form 12 December 2017; Accepted 17 December 2017. 
pro-atherogenic effects ${ }^{7}$. Apolipoprotein E (ApoE), a plasma protein that transports cholesterol, is involved in synapse repair, especially in response to tissue injury, and plays an important role in the maintenance of neuronal structure and cholinergic function ${ }^{8}$. Furthermore, the identification of the variant $\varepsilon 4$ of the gene ApoE as the most common genetic risk factor for late onset $\mathrm{AD}^{9}$ suggests that cholesterol may have a direct role in the pathogenesis of the disease.

Based on the important role of dyslipidemia in atherosclerosis and its possible association with $\mathrm{AD}^{10}$, a complementary study of the lipid profile addressing oxLDL levels, which is not part of the universe of conventionally-evaluated variables, was justified.

As $\mathrm{AD}$ is a multifactorial degenerative disease, and considering the evidence of the importance of dyslipidemias in neurodegenerative processes, the present study aimed to characterize a small set of patients with Alzheimer's dementia with respect to conventional lipid profile variables, plasma levels of oxLDL and ApoE polymorphism genotyping, compared with a group of elderly people without the disease.

\section{METHODS}

\section{Population study}

An observational case-control study was conducted. The groups comprised 80 elderly outpatients recruited between 2010 and 2011 at the Jenny de Andrade Faria Institute of Elderly, of the Clinical Hospital, aged between 60 and 90 years including: a) patients who showed no cognitive or functional impairment (control group; $\mathrm{n}=40$ ) who attended the same institution and b) patients with a diagnosis of $\mathrm{AD}(\mathrm{AD}$ group; $\mathrm{n}=40)$. The clinical characteristics of the patients studied were obtained from medical records. The characteristics of the groups according to gender, age and smoking showed that there was no difference between the control and $\mathrm{AD}$ groups (Table 1). Also no difference was found between the groups in relation to co-morbidities such as hypertension, diabetes mellitus and hypoglycemia (Table 2).

The use of statins and antidepressants showed significant differences between the groups. The use of a statin was more

Table 1. Description and distribution of individuals involved in the study.

\begin{tabular}{lccc}
\hline Variable & C & AD & -value \\
\hline Gender (\%) & $\mathrm{n}=40$ & $\mathrm{n}=40$ & \\
$\quad$ Female & $31(50.8 \%)$ & $30(49.2 \%)$ & 0.7931 \\
$\quad$ Male & $09(47.4 \%)$ & $10(52.6 \%)$ & \\
Age (years) & & & \\
$\quad$ Median (Q3-Q1) & $76.50(7.0)$ & $78.00(7.0)$ & $0.765^{2}$ \\
Smoking (\%) & $\mathrm{n}=37$ & $\mathrm{n}=31$ & \\
Yes & $17(63 \%)$ & $10(37 \%)$ & 0.2511 \\
$\quad$ No & $20(48.8 \%)$ & $21(51.2 \%)$ & \\
\hline n: sample number; C: control group; AD: Alzheimer's dementia group; \\
1- Asymptotic Power of Pearson's Chi-square test; 2- Mann-Whitney test.
\end{tabular}

frequent in the control group than in $\mathrm{AD}$ group, while this latter group, in turn, used more antidepressants than the control group (Table 3).

All AD patients were on cholinesterase inhibitors agents such as rivastigmine, galantamine and donepezil. Other drugs, according to their need, such as statins, antihypertensives, antidepressants, and hypoglycemic agents, among others, were also used.

\section{Selection criteria}

Individuals who participated in the study were selected by convenience. They met the criteria for clinical diagnosis performed by a multidisciplinary team including a geriatrician and neuropsychologists.

Participants aged younger than 60 or older than 90 years were excluded, as well as those with a severely altered health status that could compromise cognition, neuropsychological assessments, and complementary examinations. Participants with clinical and neuroimaging evidence of a vascular component and delirium were also excluded, as well individuals with major mobility, visual, or auditory disabilities, because such conditions would not enable us to fully apply the tests. Patients with dementia were also excluded if they had dementia secondary to other causes, non-Alzheimer dementia and moderate or advanced AD.

The diagnosis of sporadic "probable" $\mathrm{AD}$ was established according to the National Institute of Neurological and Communicative Disorders and Stroke and by the Alzheimer's

Table 2.Relationship comorbidities observed in the studied participants.

\begin{tabular}{lccc}
\hline Diseases & $\mathrm{C}$ & $\mathrm{AD}$ & $\mathrm{p}$-value \\
\hline Arterial hypertension & $(\mathrm{n}=40)$ & $(\mathrm{n}=40)$ & \\
$\quad$ Yes & $29(45.3 \%)$ & $35(54.7 \%)$ & 0.094 \\
$\quad$ No & $11(68.8 \%)$ & $05(31.2 \%)$ & \\
Diabetes mellitus & & & \\
$\quad$ Yes & $08(44.4 \%)$ & $10(55.6 \%)$ & 0.592 \\
$\quad$ No & $32(51.6 \%)$ & $30(48.4 \%)$ & \\
Hypoglycemia & & & \\
$\quad$ Yes & $08(42.1 \%)$ & $11(57.9 \%)$ & 0.431 \\
No & $32(52.5 \%)$ & $29(47.5 \%)$ & \\
\hline
\end{tabular}

n: sample number; C: control group; AD: Alzheimer's dementia group; Asymptotic Power of Pearson's Chi-square test.

Table 3. Use of statins and antidepressants by the study participants.

\begin{tabular}{cccc}
\hline Drugs & C & AD & p-value \\
\hline Statin & $(n=40)$ & $(n=40)$ & \\
Yes & $18(66.7 \%)$ & $09(33.3 \%)$ & $0.033^{*}$ \\
No & $22(41.5 \%)$ & $31(58.5 \%)$ & \\
Antidepressant & & & \\
Yes & $07(21.9 \%)$ & $25(78.1 \%)$ & $<0.0001^{*}$ \\
No & $33(68.8 \%)$ & $15(31.3 \%)$ & \\
\hline
\end{tabular}

n: sample number; C: control group; AD: Alzheimer's dementia group; Asymptotic Power of Pearson's Chi-square test; *: significant difference between $C$ and $A D$ groups. 
Disease and Related Disorders Association ${ }^{11}$ criteria, based on geriatric and neuropsychological assessments. The control group consisted of patients with other clinical problems who attended the same reference center. The elderly control group showed no neurological and neuropsychiatric diseases and no cognitive or functional decline. All participants ( $\mathrm{AD}$ and control groups) were submitted to the same study protocol and evaluated by a geriatrician and neuropsychologist with experience in applying cognitive tests. Only those participants with agreement between the clinical and neuropsychological diagnosis were included in the study. The study coordinator verified the agreement between the professionals involved in the research. The following tests were applied for the assessment of cognition, mood and functionality ${ }^{12-17}$ : Mini-mental State Examination, Geriatric Depression Scale (15 item version), Pfeffer Functional Activities Questionnaire, Neuropsychiatric Inventory Questionnaire, Clinical Dementia Rating scale, Mattis Dementia Rating Scale, digit span test, Corsi cubes, Token test, Rey Auditory Verbal Learning Test, frontal assessment battery, and the London Tower test. Due to the low educational level of the population in the study, the neuropsychological assessment battery included cognitive tests suitable for this aspect of the sample. All the neuropsychological/functional tools were adapted to and/or validated for Brazilian Portuguese. The cut-off points were considered according to their education level. After clinical evaluation, participants were submitted to laboratory tests to identify clinical conditions, and to exclude other causes for cognitive or functional impairment. The $\mathrm{AD}$ group was submitted to structural neuroimaging (computed tomography and nuclear magnetic resonance) to exclude another structural etiology and to contribute to the confirmation of the $\mathrm{AD}$ diagnosis.

\section{Laboratory evaluation}

Blood samples of all participants were collected in the morning after 12-14 hours of fasting, to obtain serum and plasma. Samples were processed within two hours post-collection. The EDTA-plasma samples were frozen at $-80^{\circ} \mathrm{C}$ until the time of testing.

The level of oxLDL was determined using the OX-LDL-C Kit/MDA adduct ELISA kit from Immundiagnostik, Germany. Determining absorption of the samples was performed with an ELISA reader at $450 \mathrm{~nm}$, using a Versamax Microplate Reader-Molecular Device. The TC, HDL-C and triglycerides (TG) were measured in serum using BIOCLIN" reagents. ApoE gene polymorphism was investigated using polymerase chain reaction-restriction fragment length polymorphism with primers and the methodology described by Tsukamoto et al. ${ }^{18}$

\section{Statistical analysis}

Data were analyzed using the Statistical Software Package for Social Sciences version 13.0, with $p<0.05$ considered significant for all analyses. Data were analyzed for distribution by the Shapiro-Wilks test. The results were presented as mean and standard deviation when there was normal distribution and as median and interquartile range, in the case of non-normal distribution. The following tests for comparison between the groups were used:

a) qualitative variables, such as statin and antidepressant use, and the presence or absence of the $\varepsilon 4$ allele, were analyzed by the Asymptotic Power of Pearson's Chi-square test; b) continuous variables were analyzed using the Student's t-test when the data showed normal distribution and the Mann-Whitney test for non-normal distribution.

\section{Ethical considerations}

The study was approved by the Research Ethics Committee of the Federal University of Minas Gerais (ETIC 0118.0.203.000-10) and the Department of Research and Extension in Education of the Hospital das Clínicas of the Federal University of Minas Gerais. Informed consent was obtained from all participants or their caregivers before being included in the study sample.

\section{RESULTS}

Eighty individuals were included between 2010 and 2011; 40 in the $\mathrm{AD}$ group and 40 in the control group.

\section{Lipid plasma levels, oxLDL profile and polymorphism of the ApoE gene}

Plasma levels of TG, TC and fractions, as well as oxLDL are shown in Table 4. It was observed that TG, VLDL and oxLDL had significantly higher values in the control group when compared to the $\mathrm{AD}$ group, while the TC, HDL-C and LDL-C levels were not different between the groups. When comparing oxLDL levels in the control and $\mathrm{AD}$ groups separately according to comorbidities, no significant difference was observed between the groups (data not shown). A higher

Table 4. Lipid plasma levels, oxLDL profiles and ApoE $\& 4$ carriers in control and AD groups. $(n=40)$.

\begin{tabular}{|c|c|c|c|}
\hline Variable & C & $A D$ & $\mathrm{p}$-value \\
\hline $\mathrm{TC}(\mathrm{mg} / \mathrm{dL})$ & $165.32 \pm 34.03$ & $157.01 \pm 24.91$ & $0.216^{1}$ \\
\hline $\mathrm{TG}(\mathrm{mg} / \mathrm{dL})$ & $110.50(76.80)$ & $69.57(35.70)$ & $<0.0001^{2 *}$ \\
\hline $\mathrm{HDL}-\mathrm{C}(\mathrm{mg} / \mathrm{dL})$ & $49.12(18.63)$ & $46.41(15.20)$ & $0.268^{2}$ \\
\hline VLDL (mg/dL) & $22.10(15.35)$ & $13.91(7.13)$ & $<0.0001^{2 *}$ \\
\hline LDL-C (mg/dL) & $88.57 \pm 28.15$ & $95.16 \pm 25.01$ & $0.272^{1}$ \\
\hline $\mathrm{oxLDL}(\mathrm{ng} / \mathrm{mL})$ & $126.32(122.30)$ & 71.05 (100.50) & $0.016^{2 \star}$ \\
\hline$\varepsilon 4$ carrier & $12(36.4 \%)$ & $21(63.6 \%)$ & $0.041^{3 *}$ \\
\hline$\varepsilon 4$ non-carrier & $28(59.6 \%)$ & $19(40.4 \%)$ & \\
\hline \multicolumn{4}{|c|}{$\begin{array}{l}\text { n: sample number; C: control group;AD: Alzheimer's dementia group; TC: tota } \\
\text { cholesterol; TG: triglycerides; HDL-C: high density lipoprotein cholesterol } \\
\text { VLDL: very low density lipoprotein cholesterol; LDL: low density lipoprotein } \\
\text { cholesterol; 'Student's t-test; }{ }^{2 M a n n} \text { Whitney test; }{ }^{3} \text { Asymptotic Power of } \\
\text { Pearson's Chi-square test; * significant difference between C and AD groups } \\
\text { Values in mean } \pm \text { standard deviation or median (Q3-Q1). }\end{array}$} \\
\hline
\end{tabular}


frequency of the ApoE $\varepsilon 4$ allele carrier was observed in the $\mathrm{AD}$ group when compared to the control group (Table 4).

\section{DISCUSSION}

In our study the patients were sequentially selected according to their order of admission in the Reference Center for the Elderly, with a clear predominance of women, which is explained by the feminization process of aging. Regarding gender, age, comorbidities and some of the drugs used by participants of the present study, there was no difference between the control and $\mathrm{AD}$ groups, which reduces bias interpretation of the main results of this report, for the conventional and oxLDL lipid profiles (Table 1, 2 and 4).

The main objective of the present study was to evaluate the lipid profile and oxLDL levels in $\mathrm{AD}$ patients compared to controls. It was observed that values were within the recommended cut-off points in both groups. However, the AD group showed lower levels of TG and VLDL compared to the control group. On other hand, the use of polypharmacy may have provoked the analytical and biological interference of some of these drugs on the levels of some of the biomarkers evaluated. In this context, it is noteworthy that the use of certain drugs by patients diagnosed with $\mathrm{AD}$ may interfere with the level of certain biomarkers, and the oxLDL may be an example of the interference of drugs on these levels. According Sinem et al. ${ }^{19}$, short-term therapy (7.5 \pm 1.5 months) with acetylcholinesterase inhibitors in $\mathrm{AD}$ patients resulted in a reduction of oxLDL compared to the baseline. These authors also reported that the use of antipsychotics combined with acetylcholinesterase inhibitor drugs may lead to reduced oxLDL levels in patients with $\mathrm{AD}$, compared with the group taking only cholinesterase inhibitors ${ }^{19}$. On other hand, oxLDL levels may interfere with the efficacy of acetylcholinesterase inhibitors, since they can increase the acetylcholinesterase activity, resulting in the increased production of reactive oxygen species ${ }^{20}$. According to Yamchuen et al. ${ }^{20}$, mildly- and fully-oxidized LDL were cytotoxic in dose- and time-dependent patterns in SH-SY5Y neuroblastoma cell culture, which reduces central cholinergic transmission. According to their report, oxLDL (10-200ng/ $\mathrm{mL}$ ) is capable of increasing the activity of acetylcholinesterase after four and 24 hours of treatment. This increased activity has been implicated in the progression of $\mathrm{AD}$. It should be noted that acetylcholinesterase inhibitors have been widely used to improve cholinergic transmission at the brain level ${ }^{21}$, thus enhancing cognitive status. Therefore, there are indications that drugs such as acetylcholinesterase inhibitors may interfere with oxLDL levels. It is important to note that all $\mathrm{AD}$ patients were using this medication. However, further studies are necessary to confirm these previous findings and their clinical importance as, in cases where plasma levels of oxLDL are high, conventional treatment with acetylcholinesterase inhibitor agents may not achieve the desired effect.
With regard to therapy, treatment should be initiated through the use of a cholinesterase inhibitor when an individual meets the diagnostic criteria for $\mathrm{AD}$. On the other hand, due to the depressive symptoms in many of these elderly patients, antidepressants were prescribed. Some evidence has suggested that statins, drugs widely used in the treatment of cardiovascular disorders to lower cholesterol levels, present a therapeutic potential in $\mathrm{AD}^{22}$. Elderly controls who use statins in a significantly different way to $\mathrm{AD}$ patients may be benefiting in some way from the use of this drug, especially if they began their use in middle age. Based on the literature ${ }^{2}$, it has been suggested that the use of statins may be delaying and/ or softening the neurodegenerative process. Thus, the optimization of therapy for $\mathrm{AD}$ might be obtained by incorporating pharmacogenomic and pharmacogenetic protocols ${ }^{23}$.

Atherosclerosis has also been associated not only with an increased incidence of $\mathrm{AD}$, but also with vascular dementia ${ }^{24}$. Therefore, risk factors for atherosclerosis, such as increased oxLDL, may also predispose the patient to $\mathrm{AD}$ and vascular dementia. Usually, $\mathrm{AD}$ patients are under the guidance of their caregivers and also use lipid-lowering drugs for control of TC and atherogenic fractions, which may explain, in part, the lack of difference in TC, HDL-C and LDL-C levels between the groups in this study.

Consistent with the main tone of this study, it is also important to emphasize that TG values were higher in the elderly without $\mathrm{AD}$ compared with the values obtained for those with $\mathrm{AD}$. In this respect, it should be mentioned that the living habits of $\mathrm{AD}$ patients are quite restrictive. The intake of high-calorie foods and others raising the lipid profile components are reduced, which has often contributed to weight loss in these patients. In addition, it should be also considered, that a tendency towards higher levels of LDL-C in the $\mathrm{AD}$ group compared to the control group, although not significant, may be a reflection of the increased use of statins in the latter.

In the present study, a higher frequency of the $\varepsilon 4$ allele of the ApoE gene in patients with $\mathrm{AD}$ was also observed, compared to the frequency in the control group, which reinforces the importance of genetic factors in the development of $\mathrm{AD}$. The mechanisms linking $\mathrm{AD}$ to the $\varepsilon 4$ allele are not yet fully understood. The data in the literature suggest a correlation between infarcts of small brain vessels and protease activity degrading the $\beta$-amyloid peptide in carriers of the $\varepsilon 4$ allele $^{25}$. Koffie et al. ${ }^{26}$, in a more detailed analysis, revealed that patients with $\mathrm{AD}$ carrying the ApoE $\varepsilon 4$ allele have a significantly higher $\beta$-amyloid oligomeric load leading to exacerbated synapse losses compared to ApoE $\varepsilon 3$ patients. However, it should be noted that the levels of oxLDL were not different between those with and without the $\varepsilon 4$ allele ( $p=0.363$ ). In this respect, this genetic factor does not seem to interfere with the levels of oxLDL according to our data.

An important limitation of this study is the lack of information on the levels of the different parameters of the lipid profile when the patients investigated in the present study were middle-aged. Similarly, it is not known when 
comorbidities were diagnosed in the $\mathrm{AD}$ patients at the time of blood collection. The lack of data related to drugs used by patients in middle-age may also be an important limitation of the present investigation. Another limitation of this study is the lack of a group of patients with $\mathrm{AD}$ who were not using acetylcholinesterase inhibitor drugs, which prevented a comparative analysis of the levels of oxLDL between patients who did, or did not, use the drug. Thus, our data suggests that the evaluation of oxLDL does not add any additional information to the prognosis and/or monitoring of AD. Moreover, the statin use interfered in the lipid profile interpretation in both groups.

Thus, further studies are needed to elucidate the association between oxLDL and $\mathrm{AD}$ and, especially, the interaction between the lipid profile and drugs prescribed in conventional treatment protocols.
In conclusion, the data analyzed did not reveal significant differences in the lipid profile, including the levels of oxLDL. However, the importance of lipid changes in the genesis of the disease cannot be excluded. Nevertheless, the ApoE $\varepsilon 4$ allele was found significantly more frequently in patients with $\mathrm{AD}$, which is in agreement with previous findings in the literature, but this genetic component did not change the levels of oxLDL.

\section{ACKNOWLEDGMENTS}

The authors thank the medical team and neuropsychologists of the Elderly Clinic of Instituto Jenny de Andrade Faria de Atenção à Saúde do Idoso, Hospital das Clínicas da Universidade Federal (UFMG), Brazil, as well as to the patients and elderly who generously contributed to this study.

\section{References}

1. Launer LJ, White LR, Petrovitch H, Ross GW, Curb JD. Cholesterol and neuropathologic markers of AD: a population-based autopsy study. Neurology. 2001 Oct;57(8):1447-52. https://doi.org/10.1212/WNL.57.8.1447

2. Wanamaker BL, Swiger KJ, Blumenthal RS, Martin SS. Cholesterol, statins, and dementia: what the cardiologist should know. Clin Cardiol. 2015 Apr;38(4):243-50. https://doi.org/10.1002/clc.22361

3. Escargueil-Blanc I, Salvayre R, Nègre-Salvayre A. Necrosis and apoptosis induced by oxidized low density lipoproteins occur through two calcium-dependent pathways in lymphoblastoid cells. FASEB J. 1994 Oct;8(13):1075-80.

4. Aldred S, Bennett S, Mecocci P. Increased low-density lipoprotein oxidation, but not total plasma protein oxidation, in Alzheimer's disease. Clin Biochem. 2010 Feb;43(3):267-71. https://doi.org/10.1016/j.clinbiochem.2009.08.021

5. Huang WJ, Zhang X, Chen WW. Role of oxidative stress in Alzheimer's disease. Biomed Rep. 2016 May;4(5):519-22. https://doi.org/10.3892/br.2016.630

6. Pirillo A, Norata GD, Catapano AL. LOX-1, OxLDL, and atherosclerosis. Mediators Inflamm. 2013;2013:ID152786. https://doi.org/10.1155/2013/152786

7. Tsai NW, Lee LH, Huang CR, Chang WN, Chang YT, Su YJ et al. Statin therapy reduces oxidized low density lipoprotein level, a risk factor for stroke outcome. Crit Care. 2014 Jan;18:R16. https://doi.org/10.1186/cc13695

8. Munoz DG, Feldman H. Causes of Alzheimer's disease. CMAJ. 2000 Jan;162(1):65-72.

9. Laws SM, Hone E, Gandy S, Martins RN. Expanding the association between the APOE gene and the risk of Alzheimer's disease: possible roles for APOE promoter polymorphisms and alterations in APOE transcription. J Neurochem. 2003 Mar;84(6):1215-36. https://doi.org/10.1046/j.1471-4159.2003.01615.x

10. Sato N, Morishita R. Roles of vascular and metabolic components in cognitive dysfunction of Alzheimer disease: short- and long-term modification by non-genetic risk factors. Front Aging Neurosci. 2013 Nov;5:64. https://doi.org/10.3389/fnagi.2013.00064

11. Blacker D, Albert MS, Bassett SS, Go RC, Harrell LE, Folstein MF; The National Institute of Mental Health Genetics Initiative. Reliability and validity of NINCDS-ADRDA criteria for Alzheimer's disease. Arch Neurol. 1994 Dec;51(12):1198-204. https://doi.org/10.1001/archneur.1994.00540240042014
12. Folstein MF, Folstein SE, McHugh PR. "Mini-mental state”: a practical method for grading the cognitive state of patients for the clinician. J Psychiatr Res. 1975 Nov;12(3):189-98. https://doi.org/10.1016/0022-3956(75)90026-6

13. Almeida OP, Almeida SA. [Reliability of the Brazilian version of the Geriatric Depression Scale (GDS) short form]. Arq Neuropsiquiatr. 1999 Jun;57 2B:421-6. Portuguese. https://doi.org/10.1590/S0004-282X1999000300013

14. Pfeffer RI, Kurosaki TT, Harrah CH Jr, Chance JM, Filos S. Measurement of functional activities in older adults in the community. J Gerontol. 1982 May;37(3):323-9. https://doi.org/10.1093/geronj/37.3.323

15. Camozzato AL, Godinho C, Kochhann R, Massochini G, Chaves ML. Validity of the Brazilian version of the Neuropsychiatric Inventory Questionnaire (NPI-Q). Arq Neuropsiquiatr. 2015 Jan;73(1):41-5. https://doi.org/10.1590/0004-282X20140177

16. Montaño MB, Ramos LR. Validity of the Portuguese version of clinical dementia rating. Rev Saude Publica. 2005 Dec;39(6):912-7. https://doi.org/10.1590/S0034-89102005000600007

17. Mattis S. Dementia rating scale: professional manual. Florida: Psychological Assessment Resources; 1988.

18. Tsukamoto K, Watanabe T, Matsushima T, Kinoshita M, Kato H, Hashimoto Y et al. Determination by PCR-RFLP of apo E genotype in a Japanese population. J Lab Clin Med. 1993 Apr;121(4):598-602.

19. Sinem F, Dildar K, Gökhan E, Melda B, Orhan Y, Filiz M. The serum protein and lipid oxidation marker levels in Alzheimer's disease and effects of cholinesterase inhibitors and antipsychotic drugs therapy. Curr Alzheimer Res. 2010 Aug;7(5):463-9. https://doi.org/10.2174/156720510791383822

20. Yamchuen P, Aimjongjun S, Limpeanchob N. Oxidized low density lipoprotein increases acetylcholinesterase activity correlating with reactive oxygen species production. Neurochem Int. 2014 Dec;78:1-6. https://doi.org/10.1016/j.neuint.2014.07.007

21. Tayeb HO, Yang HD, Price BH, Tarazi FI. Pharmacotherapies for Alzheimer's disease: beyond cholinesterase inhibitors. Pharmacol Ther. 2012 Apr;134(1):8-25. https://doi.org/10.1016/j.pharmthera.2011.12.002

22. Tong XK, Lecrux C, Hamel E. Age-dependent rescue by simvastatin of Alzheimer's disease cerebrovascular and memory deficits. J Neurosci. 2012 Apr;32(14):4705-15. https://doi.org/10.1523/JNEUROSCI.0169-12.2012 
23. Cacabelos R. Pharmacogenomics in Alzheimer's disease. Methods Mol Biol. 2008;448:213-357. https://doi.org/10.1007/978-1-59745-205-2_10

24. Hofman A, Ott A, Breteler MM, Bots ML, Slooter AJ, Harskamp F et al. Atherosclerosis, apolipoprotein E, and prevalence of dementia and Alzheimer's disease in the Rotterdam Study. Lancet. 1997 Jan;349(9046):151-4. https://doi.org/10.1016/S0140-6736(96)09328-2
25. Zhu H, Bhadelia RA, Liu Z, Vu L, Li H, Scott T et al. The association between small vessel infarcts and the activities of amyloid- $\beta$ peptide degrading proteases in apolipoprotein E4 allele carriers. Angiology. 2013 Nov;64(8):614-20. https://doi.org/10.1177/0003319712462125

26. Koffie RM, Hashimoto T, Tai HC, Kay KR, Serrano-Pozo A, Joyner D et al. Apolipoprotein E4 effects in Alzheimer's disease are mediated by synaptotoxic oligomeric amyloid- $\beta$. Brain. 2012 Jul;135(Pt 7):2155-68. https://doi.org/10.1093/brain/aws127 